\title{
Interaction of two heterocyclic Schiff bases derived from 2-acetyl pyridine on mild steel in hydrochloric acid: Physicochemical and corrosion inhibition investigations
}

\author{
M. Paulson Binsi ${ }^{a}$, Thomas K. Joby ${ }^{a^{*}}$, K. Ragi ${ }^{a}$, Varghese C. Sini ${ }^{a}$ and Johnson Reeja ${ }^{a}$ \\ a Research division, Dept. of Chemistry, St. Thomas' College(Autonomous), Thrissur, Kerala - 68000, India

\begin{tabular}{l}
\hline C H R O N I C L E \\
\hline Article history: \\
Received March 13, 2019 \\
Received in revised form \\
June 17,2019 \\
Accepted June 17, 2019 \\
Available online \\
June 17, 2019 \\
\hline Keywords: \\
Schiff base \\
Corrosion Inhibitor \\
Polarization \\
Impedance \\
Adsorption
\end{tabular} \\ acetyl pyridine phenyl hydrazone) (2APPH) and (E)-2-(1-triazylidineethyl)pyridine (or 2- \\ acetyl pyridine semicarbazone) (2APSC) were synthesized, characterized and their corrosion \\ inhibition behaviour as well as mechanism of inhibition were investigated by different \\ techniques. Structural characterization includes NMR, Mass, IR and UV-visible spectroscopy \\ and elemental analysis. Corrosion inhibition behaviour of aforesaid compounds on mild steel \\ in $1 \mathrm{M}$ hydrochloric acid was examined by electrochemical methods including potentiodynamic \\ polarization analysis and electrochemical impedance spectroscopic techniques. The \\ mechanism of corrosion inhibition was explored and supplemented by adsorption and surface \\ morphological studies. Quantum mechanical investigations on corrosion behaviour of \\ compounds were also conducted and satisfying correlation was noticed between the results of \\ corrosion measurement methods and quantum mechanical evaluations.
}

(C) 2020 by the authors; licensee Growing Science, Canada.

\section{Introduction}

The study of Schiff bases was considered as predominant research area to prevent the metal corrosion, since it is an important threat which can affect directly or indirectly on the economy ${ }^{1-4}$. Corrosion is the deterioration of metals and alloys by chemical or electrochemical means. Corrosion is considered as a universal phenomenon, omnipresent and omnipotent. In industrial fields, de-scaling, pickling etc. commonly employed for the metal surface cleaning, demands enormous amount of $\mathrm{HCl}$ and leads to metal disintegration. Many organic compounds containing azomethine $(\mathrm{C}=\mathrm{N})$ linkage act as corrosion inhibitor in acid media ${ }^{5-10}$. Schiff bases are organic compounds containing azomethine linkage and have many applications in corrosion science. The hetero atoms present in these molecules are responsible for the corrosion inhibition property for mild steel (MS), aluminium, copper and zinc in acid media ${ }^{11-18}$.

The present investigation was done to examine the corrosion inhibition efficiency and mechanism of two novel heterocyclic Schiff base molecules derived from 2-acetyl pyridine on MS in $1 \mathrm{M} \mathrm{HCl}$ solution. The experimental study was performed by different corrosion monitoring methods such as electrochemical investigations including polarization analysis and electrochemical impedance

* Corresponding author. Tel.: 8129822232

E-mail address: khodabakhshi2002@gmail.com (T. K. Joby)

(C) 2020 by the authors; licensee Growing Science, Canada

doi: $10.5267 /$ j.ccl.2019.006.005 
spectroscopic method. The corrosion inhibition mechanism of the compounds was confirmed by adsorption studies and surface morphological analysis. Quantum mechanical investigations on corrosion inhibition using Gammess software were also performed.

\section{Results and Discussion}

\subsection{Physicochemical discussions}

2APPH: Elemental analytical data calculated: C, 73.9; H, 6.16; N, 19.90\%. Found: C, 73.6; H, 6.12 ; N $19 \%$. Melting point: $220^{\circ} \mathrm{C}$. The ${ }^{1} \mathrm{Hnmr}$ spectrum of the Schiff base 2APPH exhibited nine clear peaks. The methyl protons displayed a peak at $2.42 \delta$. A weak broad peak exhibited at $10.48 \delta$ was due to the NH proton and the broadness of the peak can be explained by the effects of H-bonding and quadrupole broadening. The peaks appeared in the range 7.78- $8.72 \delta$ were assigned to the pyridine ring aromatic protons. In the ${ }^{13} \mathrm{Cnmr}$ spectrum a peak appeared at $12.1 \mathrm{ppm}$ assigned to methyl carbon atom and all 10 different type $\mathrm{sp}^{2}$ hybridized carbon atoms on aromatic ring exhibited their signals in the range 114-149ppm. Mass: Base peak at $211\left(\mathrm{M}^{+}\right)$. The clear signals appeared at $\mathrm{m} / \mathrm{z} 196,194$ and 106 were assigned due to the fragments $\left[\mathrm{C}_{12} \mathrm{H}_{10} \mathrm{~N}_{3}\right]^{+},\left[\mathrm{C}_{12} \mathrm{H}_{8} \mathrm{~N}_{3}\right]^{+}$and $\left[\mathrm{C}_{6} \mathrm{H}_{6} \mathrm{~N}_{2}\right]^{+}$respectively. IR: 1606 $\mathrm{cm}^{-1}(\mathrm{C}=\mathrm{N}), 3343 \mathrm{~cm}^{-1}(-\mathrm{N}-\mathrm{H})$. UV-vis: $28901 \mathrm{~cm}^{-1}\left(\mathrm{n} \rightarrow \pi^{*}\right), 32680 \mathrm{~cm}^{-1}\left(\pi \rightarrow \pi^{*}\right)$ and $39216 \mathrm{~cm}^{-1}\left(\pi \rightarrow \pi^{*}\right)$.

2APSC: Elemental analytical data calculated: C, 53.93; H, 5.61; N, 31.46. Found: C, 53.46; H, 5.45; $\mathrm{N}, 31.39$. Melting point: $200^{\circ} \mathrm{C}$. The eight distinct non equivalent protons of $2 \mathrm{APSC}$ exhibited eight clear peaks on ${ }^{1} \mathrm{Hnmr}$ spectrum. The three protons on $\mathrm{sp}^{3}$ hybridized carbon atom $\left(\mathrm{CH}_{3}\right)$ showed its characteristic peak at 2.31 . A broad peak observed at $3.9 \delta$ is assigned to the $\mathrm{NH}_{2}$ protons and the broadness of the peak can be explained by the effects of H-bonding and quadrupole broadening. The NH proton exhibited a peak at $10.167 \delta$ and the peaks appeared in the range 7.91- $8.80 \delta$ were assigned to the aromatic protons. A very weak peak appeared at $6.18 \delta \mathrm{can}$ be assigned to the $-\mathrm{OH}$ proton, which generates by the mechanism of tautomerism. In the ${ }^{13} \mathrm{Cnmr}$ spectrum the peaks appeared at $12.02 \mathrm{ppm}$ and $156 \mathrm{ppm}$ were displayed by methyl carbon atom and carbonyl carbon atom respectively. Mass: $\mathrm{m} / \mathrm{z}$ at $178\left(\mathrm{M}^{+}\right)$. The base peak observed at $\mathrm{m} / \mathrm{z} 134$ is assigned to the fragment $\left[\mathrm{C}_{7} \mathrm{H}_{8} \mathrm{~N}_{3}\right]^{+}$, which was generated the removal of amide group from the molecular ion. The clear signals appeared at $\mathrm{m} / \mathrm{z} 106$, 78 and 51 were assigned due to the fragments $\left[\mathrm{C}_{7} \mathrm{H}_{8} \mathrm{~N}\right]^{+},\left[\mathrm{C}_{5} \mathrm{H}_{4} \mathrm{~N}\right]^{+}$and $\left[\mathrm{C}_{4} \mathrm{H}_{3}\right]^{+}$respectively. IR: 1608 $\mathrm{cm}^{-1}(\mathrm{C}=\mathrm{N}), 3176 \mathrm{~cm}^{-1}(-\mathrm{N}-\mathrm{H})$. UV-vis: $29142 \mathrm{~cm}^{-1}\left(\mathrm{n} \rightarrow \pi^{*}\right), 34013 \mathrm{~cm}^{-1}\left(\pi \rightarrow \pi^{*}\right)$ and $39370 \mathrm{~cm}^{-1}\left(\pi \rightarrow \pi^{*}\right)$.

\subsection{Corrosion Inhibition Studies}

\subsubsection{Gravimetric studies}

Weight loss analysis of mild steel was performed by immersing metal coupons of $1 \mathrm{~cm}^{2}$ area in $1 \mathrm{M}$ $\mathrm{HCl}$ solution for $24 \mathrm{hrs}$ without and with the prepared Schiff bases at different concentrations. The percentage of inhibition of the prepared Schiff bases 2APPH and 2APSC are recorded in the table 1. From the analytical studies conducted it is evident that there is a significant increase in the corrosion inhibition efficiency with the introduction of Schiff bases in different concentrations in the corroding $1 \mathrm{M} \mathrm{HCl}$ solution for the mild steel examined. Thus the prepared Schiff bases under study have the capacity to efficiently inhibit metallic disintegration of mild steel in the acidic medium even at very low concentration. The inhibiting Schiff bases 2APPH and 2APSC exhibited more than 80 percent inhibition efficiency at all examined concentrations as evident from the experimental results. However, inhibitor 2APPH performed marginally higher efficiency at all concentrations and a maximum inhibition efficiency of $95.64 \%$ was achieved at $1 \mathrm{mM}$ concentration. 
Table 1. Inhibition efficiency of mild steel in the presence and absence of $2 \mathrm{APPH}$ and $2 \mathrm{APSC}$ in $1 \mathrm{M} \mathrm{HCl}$ for $24 \mathrm{hrs}$

\begin{tabular}{lccccc}
\hline & \multicolumn{5}{c}{ Con $(\mathrm{mM})$} \\
\cline { 2 - 6 } Schiff base & 0.2 & 0.4 & 0.6 & 0.8 & 1 \\
\hline 2APPH & 88.99 & 91.43 & 94.31 & 95.09 & 95.64 \\
2APSC & 81.12 & 86.98 & 89.23 & 91.64 & 94.71 \\
\hline
\end{tabular}

\subsubsection{Electrochemical Impedance Spectroscopic studies (EIS)}

The corrosion behaviour of $\mathrm{MS}$ in $1 \mathrm{M} \mathrm{HCl}$ without and with inhibitor was examined using impedance spectroscopic analysis at $30^{\circ} \mathrm{C}$. Fig. 1 and Fig. 2 represent the Nyquist plots and Bode plots of two Schiff bases 2APPH and 2APSC respectively. The impedance parameters including double layer capacitance $\left(C_{d l}\right)$, solution resistance $\left(R_{s}\right)$ and percentage of inhibition efficiency $\left(\eta_{\text {EIS\% }}\right)$ were evaluated from the values of charge transfer resistance $\left(\mathrm{R}_{\mathrm{ct}}\right)$ and tabulated in Table 1 . At both higher and lower frequencies the capacitance loop intercepts the real axis. These intercepts at the high frequency end represents the solution resistance $\left(R_{s}\right)$ and at the lower frequency end represent the sum of $R_{s}$ and $R_{c t}$. The difference between these intercepts can be calculated to find out $R_{\mathrm{ct}}$ which is the measurement of the electron transfer that takes place on the exposed metallic surface under analysis and is inversely proportional to the corrosion rate of the surface.

The study of impedance behaviour was carried out by electric models which helped to evaluate numerical measurements for the chemical and physical properties of the corresponding electrochemical system under investigation. The equivalent circuit that exactly fit to the EIS curves generally consisted of a double solution resistance $R_{s}$, charge transfer resistance $R_{c t}$ and double layer capacitance $C_{d l}$ (Figure 3). Generally, all the Nyquist plots were observed in semicircles and showed some irregularities which can be ascribed to the non-homogeneous nature or roughness of the metal surface. From the Table 2 , it was observed that along with the increasing of the inhibitor concentration, $\mathrm{C}_{\mathrm{dl}}$ values were decreased and $R_{c t}$ values were increased in the case of both inhibitors. The variation in $R_{c t}$ values can be explained by the adsorption process by which the inhibition mechanism takes place. As the inhibitor concentration increases there would be a considerable increase in the amount of adsorption process. It is due to the prevention of the charge transfer of the metal atoms on the metallic surface and solution by adsorbed molecules resulting in raising the charge transfer resistance with increasing inhibitor concentration. The lowering of $\mathrm{C}_{\mathrm{dl}}$ values with increase in the inhibitor concentration can be associated with the reduction of local dielectric constant values and rise in the thickness of electrical double layer. These observations testify the inhibitor action at the solution-metal interface.

Table 2. Electrochemical impedance parameters of MS corrosion with and without Schiff bases $2 \mathrm{APPH}$ and $2 \mathrm{APSC}$ in $1 \mathrm{M} \mathrm{HCl}$

\begin{tabular}{ccccc}
\hline Schiff base & $\mathrm{C}(\mathrm{mM})$ & $\mathrm{R}_{\mathrm{ct}}\left(\Omega_{\mathrm{cm}}^{2}\right)$ & $\mathrm{C}_{\mathrm{dl}}$ & $\eta_{\mathrm{EIS} \%}$ \\
\hline & 0 & 59.7 & 98.9 & \\
\cline { 2 - 5 } $2 \mathrm{APPH}$ & 0.2 & 342 & 94.1 & 82.54 \\
& 0.4 & 359 & 77.9 & 83.30 \\
& 0.6 & 395 & 77.6 & 84.88 \\
& 0.8 & 445 & 66.9 & 86.58 \\
& 1 & 826 & 54.5 & 92.70 \\
\hline \multirow{2}{*}{ APSC } & 0.2 & 231 & 102 & 74 \\
& 0.4 & 267 & 85.2 & 77.64 \\
& 0.6 & 317 & 84.7 & 81.16 \\
& 0.8 & 413 & 82.4 & 85.54 \\
& 1 & 470 & 81.6 & 87.29 \\
\hline
\end{tabular}




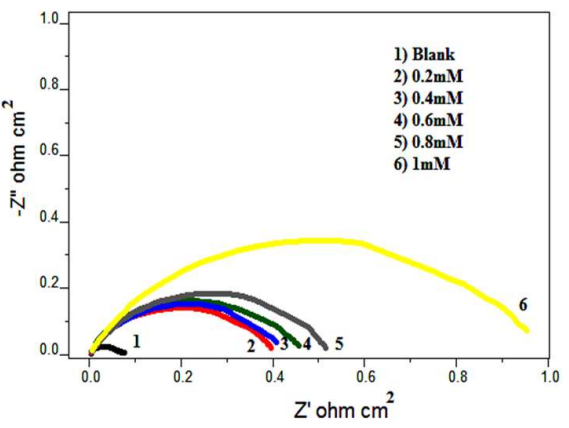

(a)

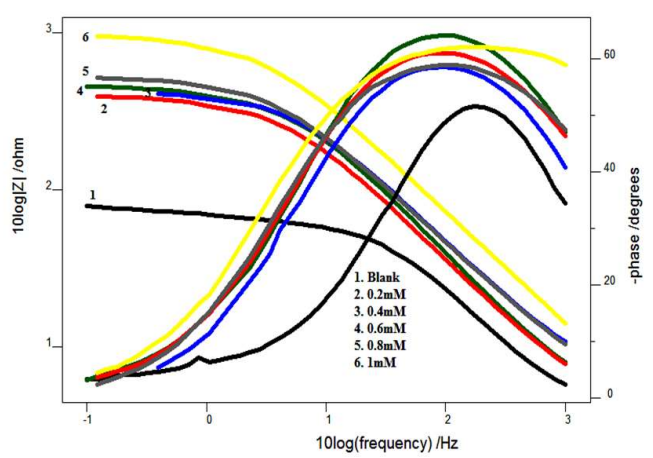

(b)

Fig. 1. a) Nyquist plots and b) Bode plots of MS corrosion with and without $2 \mathrm{APPH}$ in $1 \mathrm{M} \mathrm{HCl}$

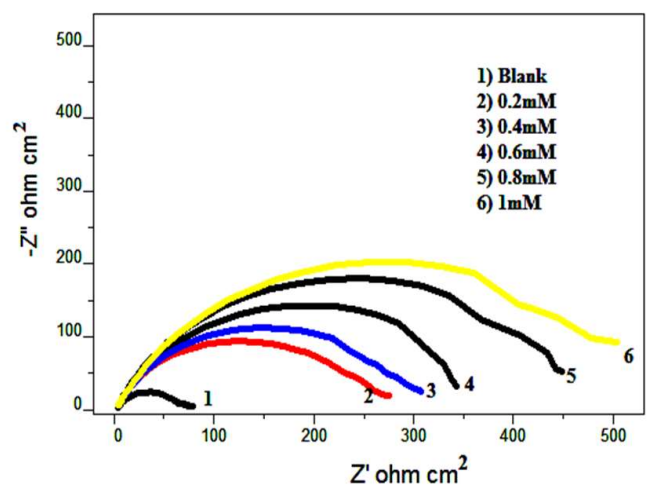

(a)

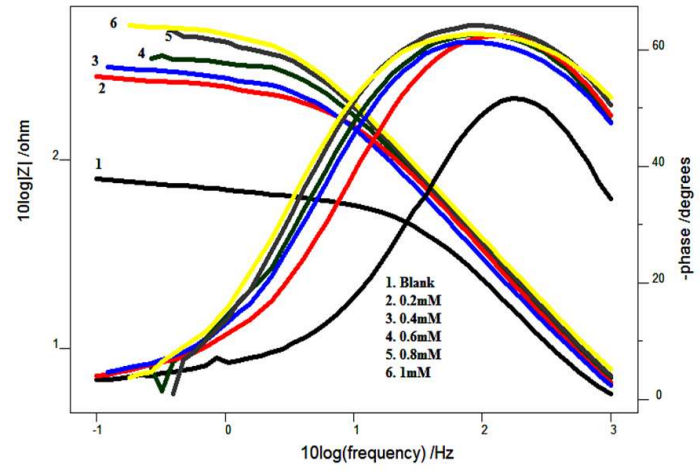

(b)

Fig. 2. a) Nyquist plots and b) Bode plots of MS corrosion with and without $2 \mathrm{APSC}$ in $1 \mathrm{M} \mathrm{HCl}$

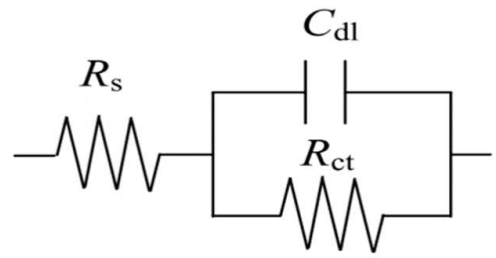

Fig. 3. Equivalent circuit for EIS measurements

From the data it is obvious that both Schiff bases 2APPH and 2APSC act as potential corrosion inhibitors in hydrochloric acid media. Both of them exhibited above $70 \%$ efficiency of corrosion inhibition and a maximum efficiency of inhibition, $92.7 \%$ was obtained for $2 \mathrm{APPH}$ at concentration of $1 \mathrm{mM}$. The efficiency of inhibition of the two Schiff bases derived from 2-acetyl pyridine obeys the order $2 \mathrm{APPH}>2 \mathrm{APSC}$.

\subsubsection{Potentiodynamic polarization studies}

Tafel extrapolation analysis and linear polarization studies were conducted to establish the impact of Schiff base compounds towards the polarization of metal specimens by the determination of polarization resistance, corrosion current density and the percentage of inhibition efficiencies. Tafel polarization curves and linear polarization curves obtained for the different concentrations are represented in the Fig. 3 and Fig. 4. The corrosion parameters -corrosion potential ( $\left.E_{\text {corr }}\right)$, corrosion 
current density $\left(I_{\text {corr }}\right)$, polarization resistance $\left(R_{p}\right)$ and inhibition efficiency percentage $\left(\eta_{\text {pol }} \%\right)$ are listed in Table 3.

Table 3. Polarization data for MS corrosion with and without inhibitors $2 \mathrm{APPH}$ and $2 \mathrm{APSC}$ in $1 \mathrm{M}$ $\mathrm{HCl}$

\begin{tabular}{|c|c|c|c|c|c|c|c|c|}
\hline \multirow[b]{2}{*}{$\begin{array}{l}\text { Schiff } \\
\text { Bases }\end{array}$} & \multicolumn{5}{|c|}{ Tafel Data } & \multicolumn{3}{|c|}{ Polarization Data } \\
\hline & $\begin{array}{l}\text { Con } \\
(\mathrm{mM})\end{array}$ & $\begin{array}{c}\mathrm{E}_{\text {corr }} \\
(\mathrm{mV} / \mathrm{SCE})\end{array}$ & $\begin{array}{c}\mathrm{I}_{\text {corr }} \\
\left(\mu \mathrm{A} / \mathrm{cm}^{2}\right)\end{array}$ & $\begin{array}{c}\mathrm{b}_{\mathrm{a}} \\
(\mathrm{mV} / \mathrm{dec})\end{array}$ & $\begin{array}{c}-\mathrm{b}_{\mathrm{c}} \\
(\mathrm{mV} / \mathrm{dec})\end{array}$ & $\eta_{\mathrm{pol}} \%$ & $\begin{array}{c}\mathrm{R}_{\mathrm{p}} \\
\text { (ohm) }\end{array}$ & $\begin{array}{c}\eta_{\mathrm{Rp}} \\
\%\end{array}$ \\
\hline \multirow{6}{*}{$2 \mathrm{APPH}$} & 0 & -498 & 360 & 122 & 150 & - & 83.23 & - \\
\hline & 0.2 & -458 & 110.8 & 86 & 188 & 69 & 232 & 64 \\
\hline & 0.4 & -425 & 103.9 & 75 & 166 & 71 & 215.4 & 61 \\
\hline & 0.6 & -455 & 87 & 81 & 191 & 76 & 282.8 & 70 \\
\hline & 0.8 & -460 & 66.4 & 72 & 164 & 82 & 327.8 & 75 \\
\hline & 1 & -450 & 34.4 & 61 & 143 & 90 & 542.8 & 85 \\
\hline \multirow{6}{*}{ 2APSC } & 0 & -498 & 360 & 122 & 150 & - & 83.23 & - \\
\hline & 0.2 & -456 & 66.6 & 71 & 163 & 82 & 321.6 & 74 \\
\hline & 0.4 & -451 & 56.2 & 64 & 155 & 84.3 & 351.8 & 76 \\
\hline & 0.6 & -460 & 55 & 66 & 144 & 84.7 & 358.4 & 76.7 \\
\hline & 0.8 & -453 & 54.2 & 67 & 150 & 84.9 & 370.4 & 77.5 \\
\hline & 1 & -448 & 53.2 & 62 & 162 & 85.2 & 367.7 & 77.7 \\
\hline
\end{tabular}

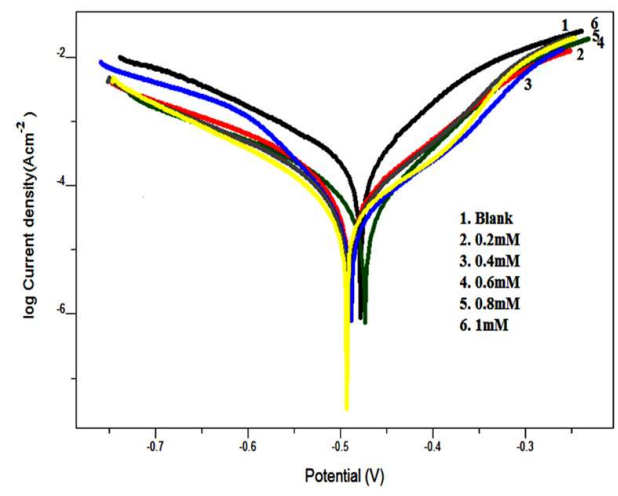

(a)

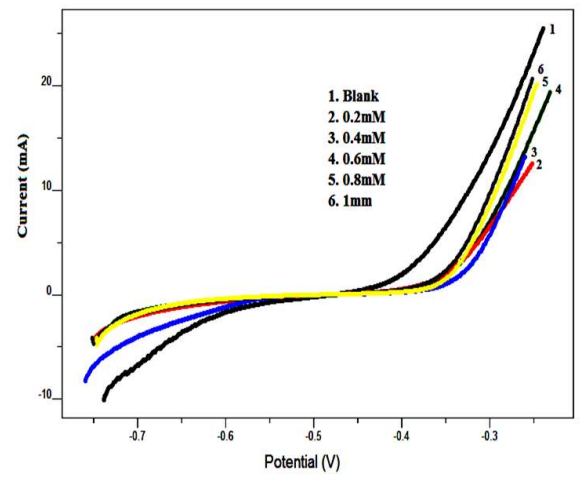

(b)

Fig. 3. a)Tafel plots and b)linear polarization curves for MS corrosion with and without of 2APPHin $1 \mathrm{M} \mathrm{HCl}$

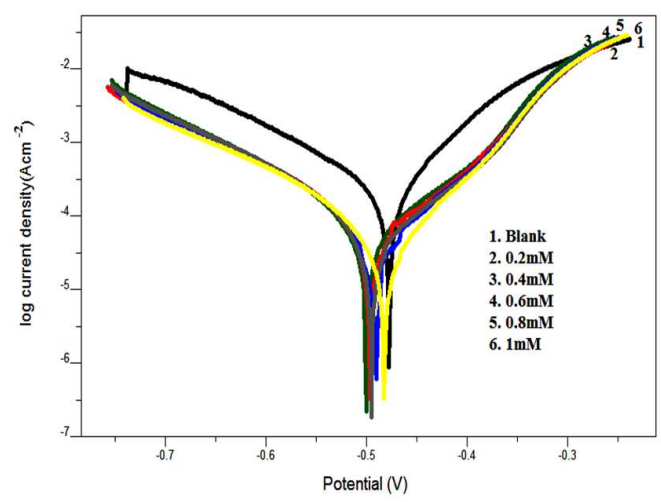

(a)

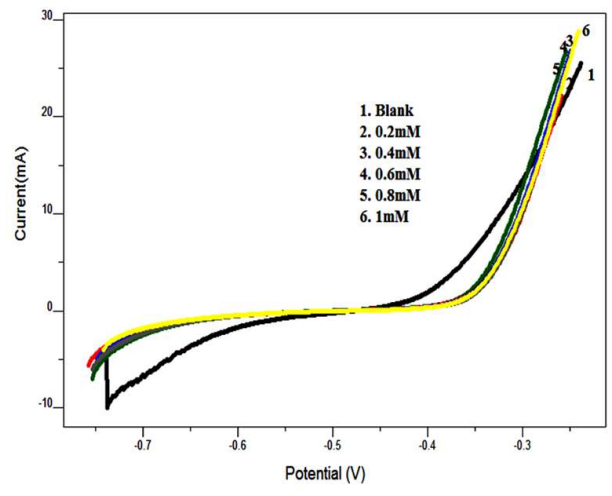

(b)

Fig. 4. a)Tafel plots and b)linear polarization curves for MS corrosion with and without of 2APSC in $1 \mathrm{M} \mathrm{HCl}$

Tafel data analysis elucidates that the values obtained for corrosion current density ( $\left.\mathrm{I}_{\text {corr }}\right)$ were significantly decreased and high inhibition efficiencies were obtained in presence of both inhibitors in 
$1 \mathrm{M} \mathrm{HCl}$ even at low concentrations. A closer examination clarified that the Schiff base $2 \mathrm{APPH}$ displayed more efficiency on MS surface as compared to 2APSC and a maximum inhibition efficiency of $85 \%$ achieved by $2 \mathrm{APPH}$ at $1 \mathrm{mM}$ concentration. This is also congruent with the data obtained in gravimetric analysis and EIS measurements. In the cases of both Schiff bases 2APPH and 2APSC the cathodic slopes exhibited predominant changes than the anodic slopes which is a clear evidence for relatively higher adsorption of these Schiff bases on the cathodic sites. Furthermore, the $\mathrm{E}_{\text {corr }}$ value was not altered $(>85)$ with respect to $\mathrm{E}_{\text {corr }}$ of blank experiment with the appreciable change in anodic or cathodic slopes in both the Schiff bases suggesting that in $1 \mathrm{M} \mathrm{HCl}$ they are mixed type inhibitors for MS.

\subsubsection{Adsorption studies}

The mechanism of adsorption of the Schiff base under study represented in figure 6 and their surface modifications can be described by invoking suitable adsorption isotherms in which the commonly used ones are Langmuir, Temkin, Frumkin and Freundlich isotherms ${ }^{19-23}$. Evaluation of adsorption parameters is done by selecting the best fit isotherm model assisted by the correlation coefficient $\left(\mathrm{R}^{2}\right)$. Fig. 5 represents the adsorption isotherms for the compounds $2 \mathrm{APPH}$ and $2 \mathrm{APSC}$ in $1 \mathrm{M} \mathrm{HCl}$. The adsorption behaviour of both $2 \mathrm{APPH}$ and $2 \mathrm{APSC}$ on MS specimens in $1 \mathrm{M} \mathrm{HCl}$ were obtained from Langmuir adsorption isotherm and it can be expressed as

$$
\frac{C}{\theta}=\frac{1}{K_{a d s}}+C
$$

where $\mathrm{C}$ is the concentration of inhibitor, $\theta$ is the fractional surface coverage and $\mathrm{K}_{\mathrm{ads}}$ is the value of adsorption equilibrium constant. This adsorption equilibrium constant, $\mathrm{K}_{\mathrm{ads}}$ mainly depends on the standard free energy of adsorption $\Delta \mathrm{G}^{0}$ ads, by the following relationship,

$$
\Delta G_{a d s}^{0}=-R T \ln \left(55.5 K_{a d s}\right)
$$

where 55.5 is the molar concentration of water, $\mathrm{R}$ is the ideal gas constant and $\mathrm{T}$ is the temperature in Kelvin.

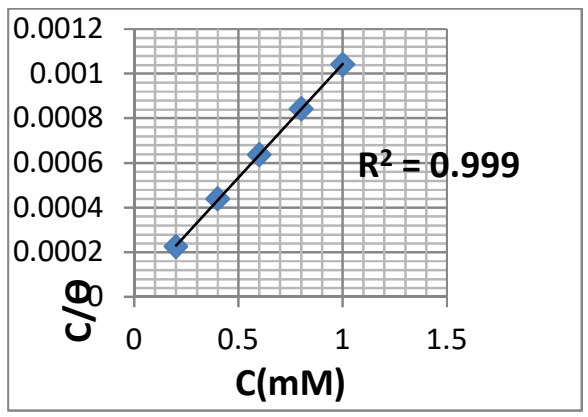

(a)

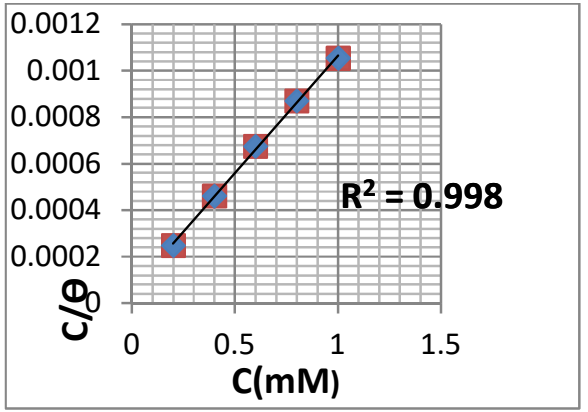

(b)

Fig. 5. Langmuir adsorption isotherms for a) $2 \mathrm{APPH}$ and b) $2 \mathrm{APSC}$ on $\mathrm{MS}$ in $1 \mathrm{M} \mathrm{HCl}$

The adsorption equilibrium constant $\mathrm{K}_{\mathrm{ads}}$ represents the measurement of the adsorption taking place on the corresponding surface. The Schiff base $2 \mathrm{APPH}$ has $\mathrm{K}_{\mathrm{ads}}$ value 33333 , which is comparatively higher than $\mathrm{K}_{\mathrm{ads}}$ value 20000 of 2APSC. It implies that the efficacy of adsorption of $2 \mathrm{APPH}$ is greater than that of 2APSC. The $\Delta \mathrm{G}^{0}$ ads values obtained for $2 \mathrm{APPH}$ and $2 \mathrm{APSC}$ are -36.13 and $-34.85 \mathrm{KJ} / \mathrm{mol}$ respectively. The $\Delta \mathrm{G}^{0}$ ads values up to $-20 \mathrm{~kJ} \mathrm{~mol}^{-1}$ indicates clearly the electrostatic attraction or physisorption between a charged molecule and a charged metal surface whereas those more negative than $-40 \mathrm{~kJ} \mathrm{~mol}^{-1}$ indicates the strong adsorption of the inhibitors on metallic surface through strong coordinate bonds or chemisorption. 


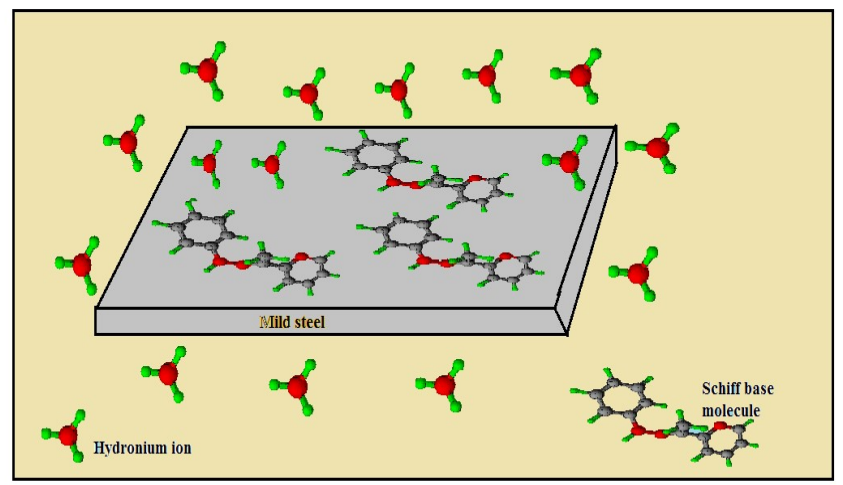

Fig. 6. Corrosion inhibition mechanism of Schiff base molecules on MS surface

\subsubsection{Surface morphological studies}

To verify the inhibition mechanism of investigated Schiff base compounds on the MS surface, morphological studies were conducted by taking SEM images of steel surfaces ${ }^{24,25}$. represents the SEM images of bare sample, metal immersed in $1 \mathrm{M} \mathrm{HCl}$, and metal immersed in $1 \mathrm{M} \mathrm{HCl}$ containing $1 \mathrm{M} 2 \mathrm{APPH}$. On close examination of figures it was evident that the MS surface was highly corroded in blank $\mathrm{HCl}$ solution. Small cracks and pits on the bare metal surface generated by the surface polishing were totally disappeared on the metal surface dipped in acid solution in the absence of Schiff base due to the intensive corrosion. The comparison of figures established that the surface damaging was appreciably decreased in the presence of $2 \mathrm{APPH}$, which indicates that the corrosion tendency was considerably suppressed due to the formation of a protective film of 2APPH through adsorption.

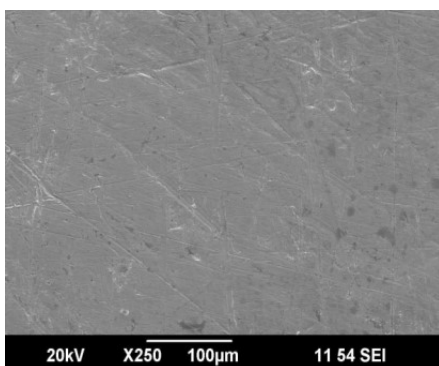

(a)

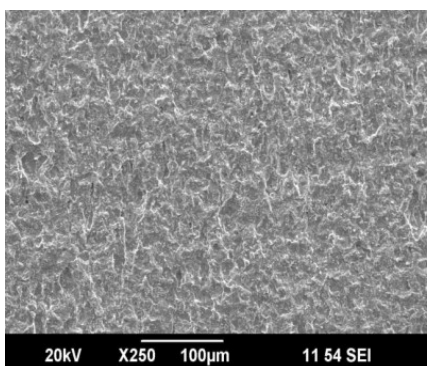

(b)

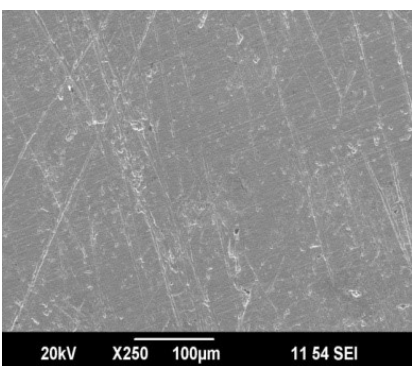

(c)

Fig. 7. a) bare sample b) metal immersed in $1 \mathrm{M} \mathrm{HCl}$ c) metal immersed in $1 \mathrm{M} \mathrm{HCl}$ containing $1 \mathrm{M}$ $2 \mathrm{APPH}$

\subsubsection{Quantum mechanical analysis}

The corrosion inhibition efficacy of Schiff base inhibitors can be correlated with the frontier molecular orbital energies. The HSAB concept (donor-acceptor interaction) between the vacant orbitals of $\mathrm{Fe}$ atoms and the filled molecular orbitals of the inhibitor compounds has an important role in the prevention mechanism of metal disintegration. The lowest $E_{\mathrm{LUMO}}-E_{\mathrm{HOMO}}(\Delta E)$ value of inhibitors is the essential quantum mechanical parameter which helps them to bind on the metal surface strongly. Quantum mechanical evaluations were carried out using DFT method by GAMMES software. Calculated quantum mechanical parameters like $E_{\text {HOMO }}, E_{\text {LUMO }}, \Delta E$, electronegativity $(\chi)$, hardness $(\eta)$ and number of transferred electrons $(\Delta N)$ for the investigated inhibitors are tabulated in table 4 . The HOMO and LUMO pictures of the inhibitors are represented in the figures 8 and 9 respectively. The $\triangle E$ between HOMO and LUMO is comparably low for 2APPH than 2APSC, which imply that $2 \mathrm{APPH}$ have predominant inhibition efficiency. These data indicate that the energy required to move electrons from HOMO of $2 \mathrm{APPH}$ to the vacant orbitals of Fe is very low. The $\Delta N$ values corresponding to the electron transfer from donor to acceptors are also evaluated from these quantum mechanical parameters 
which provide the information about interaction with the metal atoms. Optimized structures of compounds, established quantum mechanically, are represented in the figure 10. The calculations are conducted using following equations,

$$
\begin{gathered}
\chi \approx-1 / 2\left(\text { Е }_{\text {Hомо }}+\text { ELUMO }_{\text {LU }}\right) \\
\Delta N=\frac{\chi_{F e}-\chi_{i n h i b}}{2\left(\eta_{F e}+\eta_{\text {inhib }}\right)}
\end{gathered}
$$

Table 4. Quantum mechanical parameters of the Schiff base inhibitors on MS

\begin{tabular}{lrrrccc}
\hline Inhibitor & $E_{\text {HOMO }}(\mathrm{eV})$ & $E_{\text {LUMO }}(\mathrm{eV})$ & $\Delta E(\mathrm{eV})$ & $\chi$ & $\eta$ & $\Delta N$ \\
\hline 2APPH & -3.2653 & 1.0612 & 4.3265 & 1.1020 & 2.1632 & 1.36 \\
2APSC & -3.5919 & 1.1156 & 4.7075 & 102381 & 2.3537 & 1.22
\end{tabular}

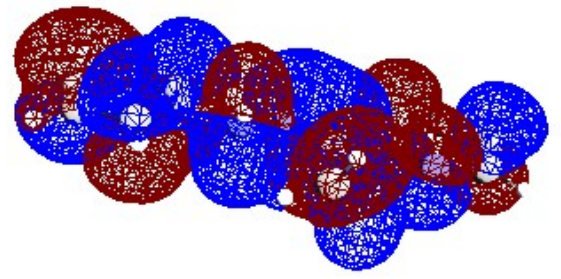

(a)

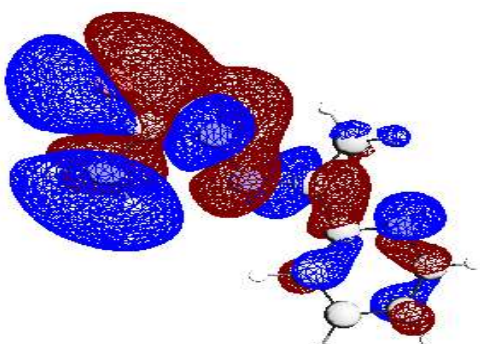

(b)

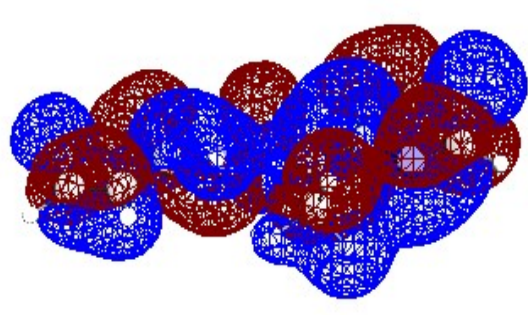

(a)

Fig. 8. HOMO of a) $2 \mathrm{APPH}$ b) $2 \mathrm{APSC}$

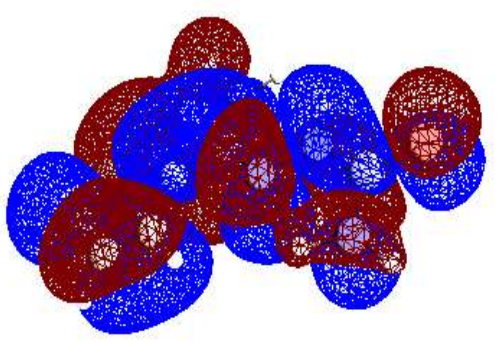

(b)

Fig. 9. LOMO of a) $2 \mathrm{APPH}$ b) $2 \mathrm{APSC}$

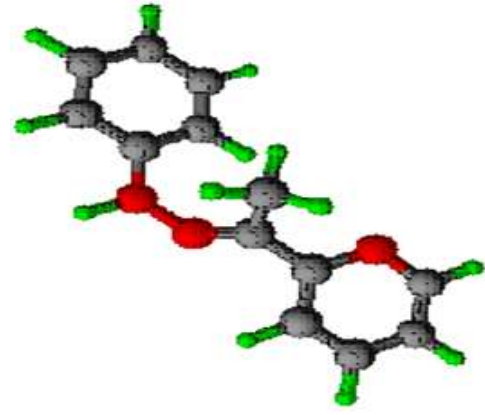

(a)

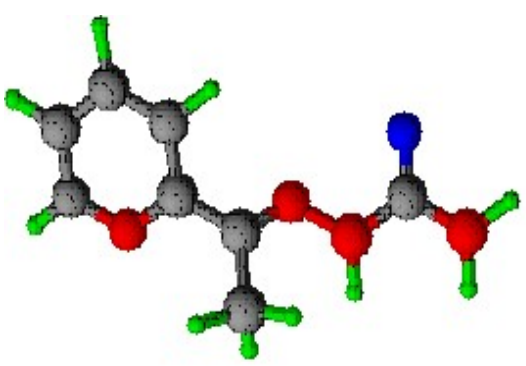

(b)

Fig. 10. Optimized structures of a) $2 \mathrm{APPH}$ b) $2 \mathrm{APSC}$ 


\section{Conclusion}

Both studied Schiff bases 2APPH and 2APSC displayed predominant corrosion inhibition efficiency on $\mathrm{MS}$ in $1 \mathrm{M} \mathrm{HCl}$ medium. According to the electrochemical analysis, corrosion inhibition efficiency of the studied compounds followed the order 2APSC $<2$ APPH. The higher efficiency of 2APPH was explained by the presence of two aromatic ring systems in the molecule. Both compounds obeyed Langmuir adsorption isotherm on MS surface. Surface morphological analysis revealed that the studied compounds form a protective barrier on MS surface and resist the metallic disintegration appreciably. Quantum mechanical investigations using Gammess software was also established that 2APPH possesses relatively higher corrosion inhibition capacity.

\section{Experimental analysis}

\subsection{Synthesis}

Heterocyclic hydrazones were synthesized by the condensation reaction of equimolar amounts of 2-acetylpyridine and amino compounds such as phenyl hydrazine and semicarbazide in ethanol medium. The resulting solutions were concentrated and the separated crystals were collected and washed with ethanol. Recrystallization from methanol gave the desired products. The products were characterized by elemental (Vario EL III Element Analyzer) analysis, mass (Shimadzu,QP 2010 GCMS), nmr ( Bruker Avance III HD, CDCl3 solvent), IR (Shimadzu affinity-1, KBr pellet method) and UV spectroscopic analyses

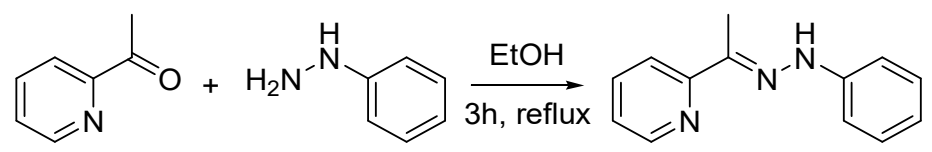

2-acetyl pyridine Phenyl hydrazine

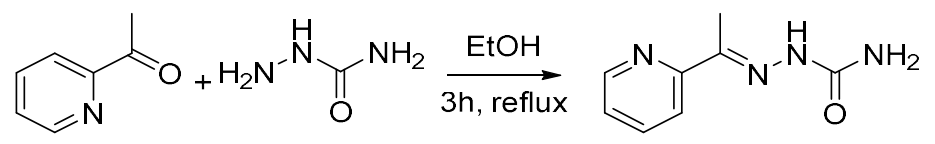

2-acetyl pyridine Semicarbazide
$2 \mathrm{APPH}$

2APSC

\subsection{Physicochemical Investigations}

C H N analysis: Carbon, hydrogen and nitrogen percentage of the Schiff bases were measured by microanalysis using Elementar make Vario EL III model CHN analyzer. Infrared spectra: The infrared spectra of the Schiff base compounds were recorded by KBr pellet method in the range of $4000-400 \mathrm{~cm}^{-}$ ${ }^{1}$ on Shimadzu model FT-IR Spectrometer (Model IR affinity-1). The infrared spectra contain the characteristic stretching frequencies which help to predict the functional groups present in the compounds. Electronic spectra: The electronic spectra of the Schiff bases were recorded on a Shimadzu UV-Visible-1800 Spectrophotometer with DMSO as solvent. The obtained data gives additional evidence for the molecular structure of Schiff bases. Mass spectra: The mass spectral studies were carried out only after the removal of the impurities present in trace amount by chromatographic method. Mass spectra were recorded using Gcms Qp-2010 plus model. NMR spectra: ${ }^{1} \mathrm{Hnmr}$ and ${ }^{13} \mathrm{Cnmr}$ studies of the compounds were recorded in $\mathrm{CDCl}_{3}$ and DMSO solvent using Bruker Avance 1ll, $400 \mathrm{MHz}$ model.

\subsection{Gravimetrical measurements}

The gravimetric measurements were carried out using ASTM standard method. Mild steel metal specimens of approximate composition $\mathrm{C}, 0.42 \%$; Mn, $0.05 \% ; \mathrm{P}, 0.01 \% ; \mathrm{S}, 0.016 \% ; \mathrm{Si}, 0.025 \%$ and rest 
Fe were used for the studies. The weight loss happened for the metal specimens were calculated for 24 hours. A blank measurement was also taken without inhibitor addition. From weight loss measurements corrosion rate and percentage of corrosion inhibition efficiency was determined. The corrosion rate and the inhibition efficiency of compounds were calculated using Eq. (1) and Eq. (2), respectively.

$$
\text { Rate of corrosion } \mathrm{W}=\frac{\mathrm{K} \times \mathrm{wt} \text {. loss in grams }}{\text { Area in sq. } \mathrm{cm} \times \text { time in Hrs } \times \text { Density }},
$$

where ' $\mathrm{K}$ ' $=87600$ (This is a factor used to convert $\mathrm{cm} /$ hour into $\mathrm{mm} / \mathrm{year}$ ), density of MS specimen = $7.88 \mathrm{~g} / \mathrm{cc}$ and the density of $\mathrm{Cu}=8.76 \mathrm{~g} / \mathrm{cc}$

Percentage of inhibition or the inhibition efficiency $(\eta)$ is given by

$$
\text { Inhibition efficiency } \eta=\frac{W-W^{\prime}}{W} \times 100 \text {, }
$$

where $\mathrm{W} \& \mathrm{~W}^{\prime}$ are the corrosion rate of the MS specimen with and without the inhibitor respectively.

\subsection{Electrochemical measurements}

The steel samples used for the electrochemical studies were abraded with different grades of silicon carbide paper, washed and dried. Different inhibitor solutions were prepared in the concentrations range of $0.2-1.0 \mathrm{mM}$ in $1 \mathrm{M} \mathrm{HCl}$ medium. Electrochemical studies were carried out using three electrode cell assembly consisting of MS as working electrode (exposed area $1 \mathrm{~cm}^{2}$ ), platinum electrode as counter electrode $\left(1 \mathrm{~cm}^{2}\right)$ and saturated calomel electrode (SCE) as reference electrode at $30^{\circ} \mathrm{C}$. For acid corrosion the working area of metal specimens were exposed to the electrolyte for $30 \mathrm{~min}$ prior to the experiment. Ivium Compact state electrochemical system together with Iviumsoft software package was used to perform the experiments.

\subsubsection{Electrochemical Impedance Spectroscopic studies (EIS)}

EIS measurements are were taken at constant potential in the frequency range from $1 \mathrm{KHz}$ to 100 $\mathrm{mHz}$ with amplitude of $10 \mathrm{mV}$ as excitation signal ${ }^{26-28}$. The percentage of inhibition calculated by the following equation,

$$
\eta_{\mathrm{EIS}} \%=\frac{\mathrm{R}_{\mathrm{ct}}-\mathrm{R}^{\prime}{ }_{\mathrm{ct}}}{\mathrm{R}_{\mathrm{ct}}} \times 100
$$

where $\mathrm{R}_{\mathrm{ct}}$ and $\mathrm{R}_{\text {ct }}$ are the charge transfer resistances of working electrode in the presence and absence of inhibitor, respectively.

\subsubsection{Potentiodynamic Polarization studies}

A potential range of +250 to $-250 \mathrm{mV}$ with a sweep rate of $1 \mathrm{mV} / \mathrm{s}$ was used for the study ${ }^{29}$. Slope analysis of Tafel curves gave the corrosion current densities and the inhibition efficiency was calculated by the following equation

$$
\eta_{\text {pol }} \%=\frac{\mathrm{I}_{\text {corr }}-\mathrm{I}_{\text {corr }}^{\prime}}{\mathrm{I}_{\text {corr }}} \times 100 \text {, }
$$

where Icorr and I'corr are corrosion current densities of the exposed area of steel rebar in the absence and presence of inhibitor respectively.

\subsection{Surface Morphological analysis}

The analysis of changes observed in the surface morphology of the metal surface helps to explain the inhibition mechanism by which the Schiff bases decrease the corrosion rate. This was carried out by recording scanning electron micrographs (SEM) of the surfaces of bare metal, metal immersed in 
acid solution (48 h) and metal immersed in inhibitor solution ( $24 \mathrm{~h})$. It was taken by the model JEOL model JSM-6390LV in the resolution value $2.00 \mathrm{x}$.

\subsection{Quantum Mechanical evaluations}

GAMMES software and DFT method were used for the determination of optimized geometry of compounds and quantum chemical evaluations. A combination of Lee-Yang-Parr nonlocal correlation functional (B3LYP) and Beck's three parameter exchange functional was employed in DFT method ${ }^{30-}$ 32.

\section{References}

1. Chaitra T. K., Mohana K. N., Gurudatt D. M., \& Tandon H. C. (2016) Inhibition activity of new thiazole hydrazones towards mild steel corrosion in acid media by thermodynamic, electrochemical and quantum chemical methods. J. Taiwan Inst. Chem. Eng., 67, 521-531.

2. Negm H. C., Elkholy Y. M., Zahran M. K., \& Tawfik S. M. (2010) Corrosion inhibition efficiency and surface activity of benzothiazol-3-ium cationic Schiff base derivatives in hydrochloric acid. Corros. Sci., 52, 3523-3536.

3. Hegazy M. A., Hasan A. M., Emara M. M., Bakr M. F., \& Youssef A. H. (2012). Evaluating four synthesized Schiff bases as corrosion inhibitors on the carbon steel in $1 \mathrm{M}$ hydrochloric acid. Corros. Sci. 65, 67-76

4. Issaadi S., Douadi T., Zouaoui A., Chafaa S., \& Khan M.A. (2011). Novel thiophene symmetrical Schiff base compounds as corrosion inhibitor for mild steel in acidic media. Corros. Sci. 53, 1484 1488.

5. Singh P., \& Quraishi M. A. (2016). Corrosion inhibition of mild steel using Novel Bis Schiff's Bases as corrosion inhibitors: electrochemical and surface measurement. Measurement, 86, 114 124.

6. Ekpe U. J., Ibok U. J., Ita B. I., Offiong O. E. \& Ebenso E. E. (1995). Inhibitory action of methyl and phenyl thiosemicarbazone derivatives on the corrosion of mild steel in hydrochloric acid. Mater. Chem. Phys. 40, 87-93

7. Kumar S. L. A., Gopiraman M., Kumar M. S., \& Sreekanth A. (2011). Inhibitory action of methyl and phenyl thiosemicarbazone derivatives on the corrosion of mild steel in hydrochloric acid. Ind. Eng. Chem. Res. 50, 7824-7832.

8. Zhang N., Fan Y., Zhang Z., Zuo J and Zhang P. (2012). Syntheses, crystal structures and anticancer activities of three novel transition metal complexes with Schiff base derived from 2acetylpyridine and 1-tryptophan. Inorg. Chem. Commun. 22, 68-72.

9. Dandia A., Gupta S. L., Singh P., \& Quraishi M. A. (2013). Ultrasound-assisted synthesis of pyrazolo[3,4-b]pyridines as potential corrosion inhibitors for mild steel in $1.0 \mathrm{M} \mathrm{HCl}$. ACS Sustain. Chem. Eng. 1, 1303-1310.

10. Vinod P. Raphael., Joby Thomas K., Shaju S., \& Paul, A. (2014) Corrosion inhibition investigations of 3-acetylpyridine semicarbazone on carbon steel in hydrochloric acid medium. Res Chem Intermidiat, 40, 2689- 2701.

11. Nam, N. D., Bui, Q. V., Mathesh, M., Tan, M. Y. J., Forsyth, M. (2013) A study of 4carboxyphenylboronic acid as a corrosion inhibitor for steel in carbon dioxide containing environments. Corros. Sci, 76, 257-266.

12. Sinha D., Tiwari AK., Singh S., Shukla G., \& Mishra P. (2008) Synthesis, characterization and biological activity of Schiff base analogues of indole-3-carboxaldehyde. Eur. J. Med. Chem. 43, $160-165$

13. Kamal C., \& Sethuraman M. G. (2012). Caulerpin- A bis-indole alkaloid as a green inhibitor for the corrosion of mild steel in $1 \mathrm{M} \mathrm{HCl}$ solution from the marine alga Caulerpa racemosa. Ind. Eng. Chem. Res. 51, 10399-10407

14. Singh A. K. (2012) Inhibition of Mild Steel Corrosion in Hydrochloric Acid Solution by 3-(4-((Z)Indolin-3-ylideneamino)phenylimino)indolin-2-one. Ind. Eng. Chem. Res. 51, 3215-3223 
15. Aby paul., Joby Thomas K., Vinod P. Raphael., \& Shaju K. S. (2012) Electrochemical and gravimetric corrosion inhibition investigations of a heterocyclic Schiff Base derived from 3formylindole. IOSR J. Appl. Chem. 1, 17-23.

16. Ganjali M. R., Poursaberi, T., Babaei, LH., \& Rouhani, S. (2001). Highly selective and sensitive copper (II) membrane coated graphite electrode based on a recently synthesized Schiff's base. Anal. Chim. Acta 440, 81-87.

17. Daoud D., Douadi T., Issaadi S., \& Chafaa S. (2014) Adsorption and corrosion inhibition of new synthesized thiophene Schiff base on mild steel X52 in HCl and H2SO4 solutions. Corros. Sci. 79, $50-58$.

18. Aounitia A., Aounitia H., Elmsellema S., Tighadouinia M., Elazzouzia S., Radiab A., Chetouanic B., Hammoutia A., \& Zarrouka. (2016) Schiff's base derived from 2-acetyl thiophene as corrosion inhibitor of steel in acidic medium. J. Taibah Univ. Sci., 10, 774-785.

19. Hamani, H., Douadi, T., Daoud, D., Al-Noaimi, M., \& Chafaa, S. (2016) Corrosion inhibition efficiency and adsorption behavior of azomethine compounds at mild steel/hydrochloric acid interface. Measurement, 94, 837-846.

20. Ateya B. G., El-Anadouli B. E., \& El-Nizamy, M. F. (1984) The adsorption of thiourea on mild steel. Corros. Sci. 24, 509-515.

21. Zhao T., \& Mu G. (1999) The adsorption and corrosion inhibition of anion surfactants on aluminium surface in hydrochloric acid. Corros. Sci. 41, 1937-1944.

22. Soltani N., Salavati H., Rasouli H., Paziresh M., \& Moghadasi A. (2016) Adsorption and corrosion inhibition effect of Schiff base ligands on low carbon steel corrosion in hydrochloric acid solution. Chem. Eng. Commun. 203, 840-854.

23. Bedair M. A.,. El-Sabbah M. M. B, Fouda A. S., \& Elaryian H. M. (2017) Synthesis, electrochemical and quantum chemical studies of some prepared surfactants based on azodye and Schiff base as corrosion inhibitors for steel in acid. Corros. Sci. 128, 54-72.

24. Palayoor, V. R., Kakkassery, J. T., Kanimangalath, S. S., \& Varghese, S. (2017) Chemical modification at the surface and corrosion inhibition response of two semicarbazones on carbon steel in $\mathrm{HCl}$ medium. Int. J. Ind. Chem., 8, 49-60.

25. Ashassi-Sorkhabi H., Shaabani B., \& Seifzadeh D. (2005) Corrosion inhibition of mild steel by some Schiff base compounds in hydrochloric acid. Appl. Surf. Sci. 239, 154-164.

26. Kuruvilla M., John S., \& Joseph A. (2016) Electroanalytical studies on the interaction of l-serinebased Schiff base, HHDMP, with copper in sulphuric Acid. J. Bio-Tribo-Corrosion 2.

27. Kumari P. P., Rao S. A., \& Shetty P. (2014) Corrosion inhibition of mild steel in $2 \mathrm{M} \mathrm{HCl}$ by a Schiff base derivative. Procedia Mater. Sci. 5, 499-507

28. Emregül K. C., \& Atakol O. (2004) Corrosion inhibition of iron in $1 \mathrm{M} \mathrm{HCl}$ solution with Schiff base compounds and derivatives. Mater. Chem. Phys. 83, 373-379

29. Bentiss F., Lagrenee M., Traisnel M., \& Hornez J. C. (1999) Corrosion inhibition of mild steel in $1 \mathrm{M}$ hydrochloric acid by 2, 5-bis (2-aminophenyl)-1, 3, 4-oxadiazole. Corrosion, 55, 968-976

30. Dalia M. Jamil., Ahamed K A-Okbi., Shaimaa B Al Baghdadi., \& Ahamed A Al Amiery. (2018) Experimental and theoretical studies of Schiff bases as corrosion inhibitor. Chem. Cen. J. 12(1), 7.

31. Vinod P. Raphael., Joby Thomas K., \& Shaju S. (2016) Monitoring the interaction of two heterocyclic compounds on carbon steel by electrochemical polarization, noise, and quantum chemical studies. Int. J. Corr. 2016, 1-10.

32. Gupta N. K., Quraishi M. A., Verma C., \& Mukherjee A. K. (2016) Green Schiff's bases as corrosion inhibitors for mild steel in $1 \mathrm{M} \mathrm{HCl}$ solution: experimental and theoretical approach. $R S C$ Adv. 6, 102076-102087.

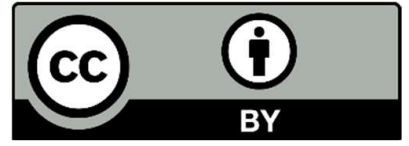

(C) 2020 by the authors; licensee Growing Science, Canada. This is an open access article distributed under the terms and conditions of the Creative Commons Attribution (CC-BY) license (http://creativecommons.org/licenses/by/4.0/). 